\title{
CLINICAL IMPROVEMENT OF COVID-19 PATIENTS WITH CONVALESCENT PLASMA THERAPY: META-ANALYSIS
}

\author{
Fathiyyatu Assa'diy Firda'), Cri Sajjana Prajna Wekadigunawan²), \\ Bhisma Murti1) \\ 1)Masters Program in Public Health, Universitas Sebelas Maret \\ 2)University of Esa Unggul, Jakarta, Indonesia
}

\begin{abstract}
Background: Convalescent plasma containing antibodies generated following pathogens' exposure has been employed in past epidemics as a means of passively transferring immunity from individuals with resolved COVID-19 infection. Furthermore, convalescent plasma may contain beneficial anti-inflammatory cytokines, defensins, and pentraxins that quell a severe inflammatory response. This study aimed to estimate clinical improvement of COVID-19 patients with convalescent plasma therapy.

Subjects and Method: A systematic review and meta-analysis was conducted by collecting articles from Google Scholar, PubMed, and Science Direct databases. The articles were filtered using PICO model, including: (1) Population= patients confirmed COVID-19, (2) Intervention= convalescent plasma therapy, (3) Comparison $=$ standard of care, and (4) Outcome= patient clinical improvement. Keywords used "Convalescent plasma therapy" OR "Convalescent plasma transfusion" AND "Clinical improvement" AND "COVID-19" OR "Coronavirus disease 2019" OR "SARS-Cov-2". The inclusion criteria were full text, matched control studies, published from 2020 to 2021, and reported risk ratio. The articles were collected using PRISMA diagram and the qualitative synthesis was assessed using Review Manager (RevMan 5.3).

Results: A meta analysis using 6 randomized controlled trial involving 902 confirmed COVID-19 patients from New York, Brazil, India, Argentina, China, England, and Spain. This study showed that convalescent plasma therapy elevated clinical improvement in confirmed COVID-19 patients, but it was statistically non-significant $(\mathrm{RR}=1.01 ; 95 \% \mathrm{CI}=$ 0.94 to $1.10 ; \mathrm{p}=0.73$ ). As indicated by $\mathrm{I}^{2}=0 \%$, we found non-significant between-study heterogeneity and estimation was done using fixed effect model.
\end{abstract}

Conclusion: Convalescent plasma therapy elevates clinical improvement in confirmed COVID-19 patients, but it was statistically non-significant.

Keywords: COVID-19, convalescent plasma therapy, clinical improvement

\section{Correspondence:}

Fathiyyatu Assa'diy Firda. Masters Program in Public Health, Universitas Sebelas Maret. Jl. Ir. Sutami 36A, Surakarta 57126, Central Java. Email: fathiyyatu.firda98@gmail.com. Mobile: 089516880479. 